\title{
Indicators of Drug-Related Community Impacts of Open Drug Scenes: A Scoping Review
}

\author{
Mohammad Bagher Saberi Zafarghandi ${ }^{a}$ Sahar Eshrati ${ }^{a}$ Vahid Rashedi ${ }^{b}$ \\ Meroe Vameghi $^{c}$ Reza Arezoomandan ${ }^{a}$ Thomas Clausen $^{d}$ Helge Waal $^{d}$

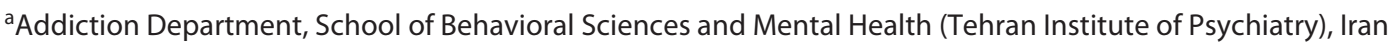

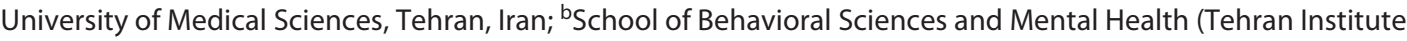 \\ of Psychiatry), Iran University of Medical Sciences, Tehran, Iran; 'Social Welfare Management Research Center, \\ University of Social Welfare and Rehabilitation Sciences, Tehran, Iran; ${ }^{\mathrm{d} N o r w e g i a n}$ Center for Addiction Research \\ (SERAF), Institution of Clinical Medicine, Faculty of Medicine, University of Oslo, Oslo, Norway
}

\section{Keywords}

Drug-related community impacts · Open drug scene .

Scoping review

\begin{abstract}
Introduction: Places where people deal and/or use drugs publicly are known as open drug scenes (ODSs). Drug-related community impacts (DRCls) refer to drug-related issues that negatively influence public and individual health, communities, businesses, and recreational and public space enjoyment. There are no well-established criteria for identification of DRCls. We therefore performed a scoping review of literature to determine DRCls indicators associated with ODSs. Methods: The review was performed using the Preferred Reporting Items for Systematic Reviews and MetaAnalysis extension for scoping reviews (PRISMA-SCP). We searched English articles in PubMed, Scopus, Web of Science, and EMBASE databases from 1990 to 2021. The keywords were drug-related crime, drug-related offense, misconduct, social marginalization, homeless drug users, open drug scene, drug-related street disorder, public nuisance, and community impact. Results: Sixty-four studies were identified. Twenty-five studies were included. Two studies
\end{abstract}

(8\%) were about drug-related public nuisance, 1 (4\%) considered drug-related social problems, 2 (8\%) focused on drug-related social disorder, and 18 studies (72\%) discussed indicators of community impacts such as crime, drug-related litter, safety, noise, and drug use in public. Two studies (8\%) included the frequency of drug use in ODSs. Discussion: $\mathrm{DRCl}$ indicators are heterogenic, and various factors affect the indicators. The factors include social mores, political discourse, and historical approaches to dealing with and using drugs. Some societies do not tolerate the existence of ODSs. In contrast, many countries have adopted harm reduction programs to manage $\mathrm{DRCls}$. Identified $\mathrm{DRCl}$ indicators were drug using and dealing in public, drug-related litter, crime, drug-related loitering, street-based income generation activities, noise, and unsafety feelings in inhabitants. To solve the problems associated with DRCls and to make a major change in ODSs, it is necessary to pay attention to the improvement of the economic conditions (e.g., employment opportunities), amendment (e.g., determine the limits of criminalization in drug use), and adoption of social policies (e.g., providing low-threshold and supportive services for homeless drug users). karger@karger.com www.karger.com/ear
(C) 2021 S. Karger AG, Basel
Correspondence to:

Sahar Eshrati, eshrati.s@gmail.com 


\section{Introduction}

Places where people use and/or deal drugs publicly are known as open drug scenes (ODSs), which have variations in sizes, locations, and visibility. Based on the literature, there are 3 types of drug scenes: hidden, concentrated, and disperse drug scenes $[1,2]$.

In addition to health impacts such as infectious diseases and drug overdose, drug-related community impacts (DRCIs) including drug-using and/or dealing in public view are the main problems of ODSs [3]. Due to differences in perception of social effects, there are ambiguities in determining the exact indicators of DRCIs [4]. According to multidisciplinary expert panels, DRCIs are a set of drug-related activities, situations, and behaviors varying in nature, scale, and drug. The DRCIs include (1) drug-related crimes in relation to regulations and laws and (2) drug-related undesirable, unpleasant, annoying, threatening or harmful, and in some cases, unacceptable activities, and behaviors. DRCIs have negative influences on businesses, daily life, and the possibility of enjoying recreational and public space for the surrounding population of ODSs, and also it is harmful for people who use drugs (PWUDs) themselves [5-7]. These problems include public drug consumption/injection, disposal of drug-related litter, overt drug-related poisoning, drug dealing in public transactions, and exposure of local children to these scenes [8].

Perception of drug-related behavior as a problem is partly influenced by the level of general tolerance. One of the challenges is determining which behaviors by different people in different societies are problematic. Some officials and people do not tolerate the existence of ODSs. In contrast, many inhabitants, civic authorities, and local businesses have adopted harm reduction programs to manage the health and social impact of these scenes $[6,8$, 9].

Drug-related public nuisance includes drug-related criminal activities and antisocial behaviors [3], and drugrelated social disorders are other specific aspects of DRCIs in ODSs. Drug-related street disorder interferes with people's enjoyment of public and recreational spaces in two ways: first, the destructive effects on the physical space like garbage disposal, and structural decay of the neighborhood. Second, the behaviors and activities are not socially acceptable. The critical indicators of the drugrelated social disorder are drug use in public, drug-related litter, loitering or socializing in public, and disorderly street-based income generation practices (e.g., sexual transactions, drug trafficking, begging, squeegee, and recycling) [7]. In the current study, the DRCIs are defined as relevant features of both drug-related social disorder and public nuisance.

In the current scoping review, DRCI indicators related to ODSs are classified. We performed a scoping review in order to investigate (1) the effect of tolerance in the perception of DRCIs, and (2) the diverse settings in which DRCIs have occurred (i.e., ODSs, neighborhoods, communities, and harm reduction centers like drug consumption room that addressed DRCIs) since there is a lack of randomized controlled trials regarding the topic of DRCI indicators [10-13].

\section{Methods}

Study Design

The review was performed using the Preferred Reporting Items for Systematic Reviews and Meta-Analysis extension for scoping reviews (PRISMA-ScP) $[10,14]$. The articles were selected based on predefined inclusion and exclusion criteria. The same search methods were used to recognize related documents in scoping reviews as those utilized in systematic reviews. Unlike a systematic review in which the data are quantitatively and qualitatively synthesized and the design quality of studies is assessed, in scoping reviews, a qualitative synthesis of articles about indicators of DRCIs related to ODSs is performed [11].

\section{Inclusion Criteria}

1. Nonexperimental or quasi-experimental ones like surveys and observational studies.

2. Published in English language.

3. Published between January 1990 and January 2021.

4. Related to known/specific ODSs like Downtown Eastside in Vancouver, Canada; Plata in Oslo, Norway; the Zeedijk area in Amsterdam, Netherlands; Platzspitze and Needle Park in Zurich, Switzerland; and Karlplatz in Vienna, Austria; or other districts that are known to hold a population of socially disadvantaged drug users and dealers.

5. Examples of DRCIs (e.g., pull effect, public drug use or dealing, drug-related public security or order, and drug-related crime).

6. Interventional studies (such as medically supervised safer injecting facility) focused on reducing DRCIs $[15,16]$.

7. First published article in the analysis when we identified multiple articles from the same study.

\section{Exclusion Criteria}

1. Reports and policy studies.

2. Studies about homeless mentally ill without any drug use.

3. Studies about mental health impacts such as risky behaviors, as well as crimes and policy for PWUDs generally (not related to ODSs).

4. Lack of access to the full text of studies.

5. Participants younger than 18 years old who are not involved in ODSs.

6. Studies with a focus on homeless children. 


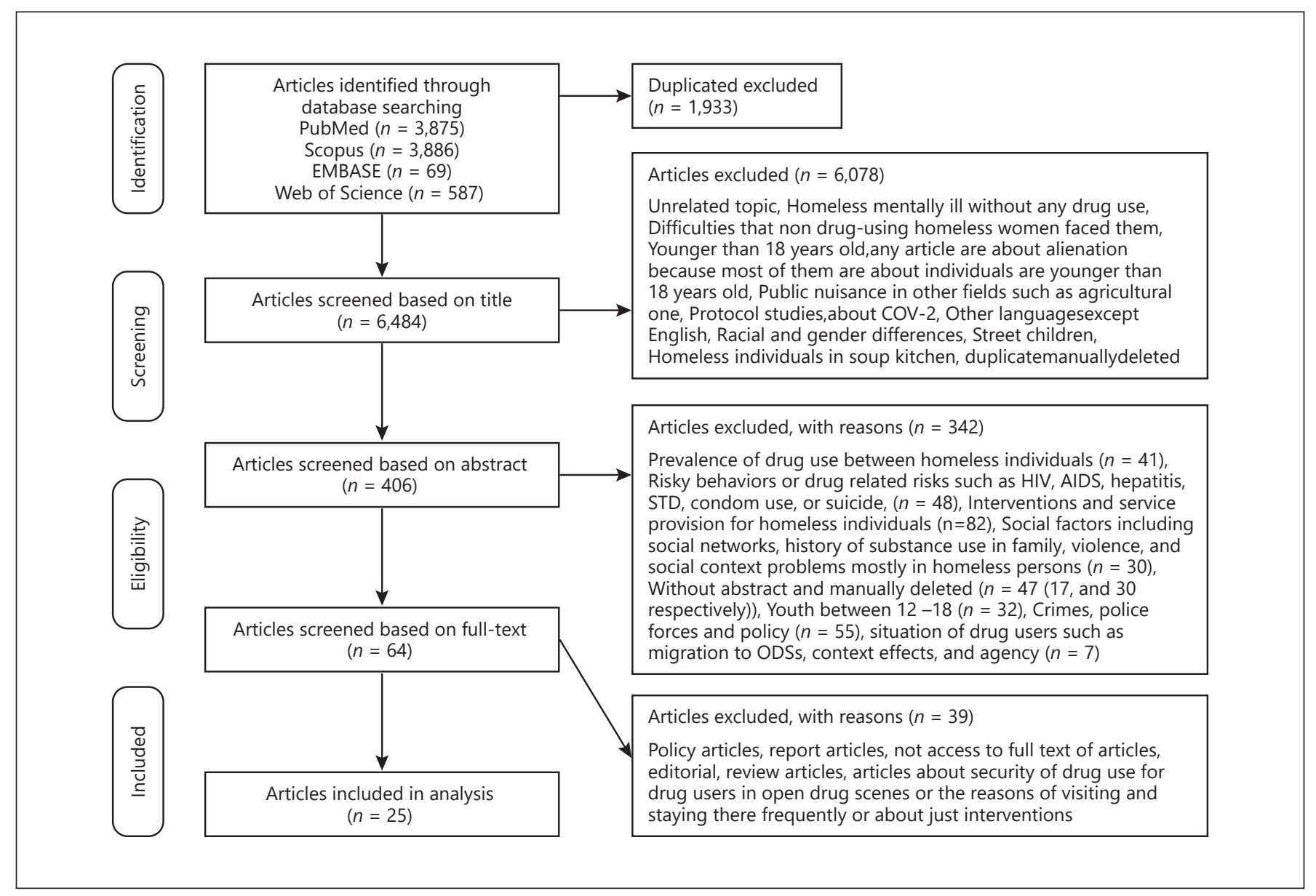

Fig. 1. Diagram depicting identification and screening of eligible articles about DRCIs of ODSs from 1990 to 2021. ODS, open drug scene; DRCI, drug-related community impact.

Data and Source Search Strategy

The study aimed to review published studies reporting the indicators of DRCIs internationally from 1990 to 2021 which were published in the English language.

\section{Search Strategy}

Four electronic databases including PubMed, Scopus, Web of Science, and EMBASE were searched. The search terms included ("drug-related crime" or "drug-related offense" or "misconduct" or "social marginalization" [Mesh] or "homeless drug users" or "drug-related street disorder" or "drug-related public nuisance" or "drug-related community impact") and ("open drug scene"). Besides, we scanned the references list of included studies [17]. We also searched the authors' personal file/website to ensure that all relevant materials had been captured.

\section{Selection of Studies}

Our search was finalized in January 2021 and duplication studies (1933) were excluded. Out of a total of 6,484 articles, 6,078 studies were excluded from the study due to the lack of relevance in the topic (e.g., agricultural harassment, nondrug using homeless peo- ple in the soup kitchen, and street children), published in a nonEnglish language, and nonresearch publication (e.g., policy or report articles and editorial papers). The remaining abstracts (406 articles) were reviewed by two coders (based on inclusion criteria), and about $90 \%$ of the abstracts were approved. Therefore, 342 articles were excluded in this stage, and 64 studies were selected for the full-text search. By reviewing the full text of the articles, 39 studies did not meet the required criteria and were excluded. The remaining 25 studies were identified as eligible for inclusion in the review (Fig. 1).

\section{Data Extraction and Analysis}

The eligible articles were studied using inductive qualitative analysis. Data including study location, methods, year of publication, sample, variables, and indicators considered as DRCIs were extracted by the expert consensus of the research team. In qualitative studies, those DRCI indicators were considered, which have been reported in at least 2 articles in order to summarize a wide range of indicators of DRCIs. In the quantitative studies, the indicators of community impacts as a non-numerical variable were considered. 
Quality Assessment

There are numerous tools to assess the methodological quality and risk of bias in randomized controlled trials; however, few are designed specifically for observational studies [18]. All studies were critically appraised by two reviewers (S.E. and V.R.). We assessed the methodological quality using different methods for quantitative and qualitative studies, as explained later.

For the item-level methodological quality assessment for each study, see online supplementary File 1 (for all online suppl. material, see www.karger.com/doi/10.1159/000519886) (quantitative studies) and online supplementary Files 2 and 3 (qualitative studies). Quantitative studies and quantitative part of studies with mixed-method were assessed using the appraisal tool for cross-sectional studies (AXIS) [19]. The forms include (i) selection procedures, (ii) baseline assessment, (iii) outcome assessment, (iv) analysis/confounding, and (v) authors' interpretation of the results affected by conflicts of interest that are rated as strong, moderate, or weak.

Qualitative studies and qualitative part of mixed-method studies were appraised using both tool adapted by Harden et al. [20] and Bromley et al. [21] . In the latter form, each study was assessed according to 18 criteria covering theoretical/epistemological issues, methodology, use of strategies to increase reliability and validity, and extent to which findings reflected participant perspectives and experiences. A final assessment sorted studies into one of 3 adjusted categories based on quality: high quality (those meeting 15 or more criteria), medium quality (those meeting between 14 and 11 criteria), and low quality (those meeting fewer than 11 criteria).

To ensure that the quality assessment tool was appropriate for the qualitative studies, the review also used a modified version of the quality assessment tool used by Harden et al. [20] that was adapted for application to qualitative studies. Each study was assessed according to 12 criteria designed to aid judgment on the extent to which study findings were an accurate representation of participants' perspectives and experiences. Studies that meet 10 or more of the assessment criteria were defined as high-quality ones. Those that meet between 7 and 9 criteria were defined as moderate quality and fewer than 7 criteria were defined as low quality. A global assessment of validity was made based on whether aspects of the study were clear, adequate, or explicit using this scale [20].

\section{Results}

\section{Features of Qualified Studies}

Figure 1 illustrates the selection process of eligible studies. Of 8,417 primary articles, 25 were found eligible (see Fig. 1). Seven cross-sectional studies were judged to be of sufficient methodological quality [7, 22-27]. The eligible publication rate was 1-2 articles annually. Studies from low- to middle-income countries, including Brazil, primarily focused on the description of drug-related public nuisance (Table 1). Studies from high-income countries such as Spain, Ireland, Canada, and the USA were mostly related to interventions that targeted DRCI indicators. Most articles stemmed from Canada (36\%) and
European countries (44\%). The majority of articles used quantitative methods (68\%) and mixed methods (24\%), and qualitative studies (8\%) were relatively infrequent. Most of the studies were cross-sectional (92\%) with 2 time series studies (8\%). According to the title of eligible studies, the main subject of articles was drug use in public and crime (44\%), and on indicators of DRCIs as a public nuisance, community impact, and street disorder (32\%). The remaining studies were about the effects of drug consumption rooms on DRCIs (24\%) (Table 2).

\section{Purpose of Studies}

The purposes of the included studies are described in Table 3. The aim of 15 studies (60\%) was description/ evaluation of the effects of interventions, such as safer drug-using facilities (as a solution to mitigate surrounding drug scene-related problems) on some types of DRCI indicators. Three additional studies (12\%) were about the perception of unsafety associated with DRCI indicators. Two articles (8\%) were focused on the characteristics of drug users in ODSs. The purpose of 5 studies (20\%) was measurement or explanation of indicators of DRCIs, such as pull effect, loitering, public injection, and street-based income generation activities.

\section{Frequency of Indicators of DRCIs in Quantitative Studies}

Table 4 shows that the main indicators of DRCIs were drug use in public (public drug use, drug-related litter, environmental changes to deter drug use, and police activities or consequences of that), drug dealing, crime and incarceration, presence of PWUDs in public space or drug-related loitering, disorderly street-based income generation activities, noise, and perception of safety.

\section{Indicators of DRCIs in Quantitative Studies}

Manifestations of Substance Use in Public

Drug Use in Public

In some studies, drug use in public has been evaluated/ described through the frequency of smoking crack in public places $[33,43]$, or drug use in public $[16,22,23,29$, $35,36]$, and injection in public $[5,27,37,38,41,42]$. According to the number of eligible articles in the study, besides disposal of drug-related paraphernalia, drug use in public was the main indicator of DRCIs.

\section{Drug-Related Litter}

Another identified domain was the problem of paraphernalia such as used foil or needles and syringes in public spaces [43]. The same concept has been studied in oth-
Saberi Zafarghandi/Eshrati/Rashedi/ Vameghi/Arezoomandan/Clausen/Waal 


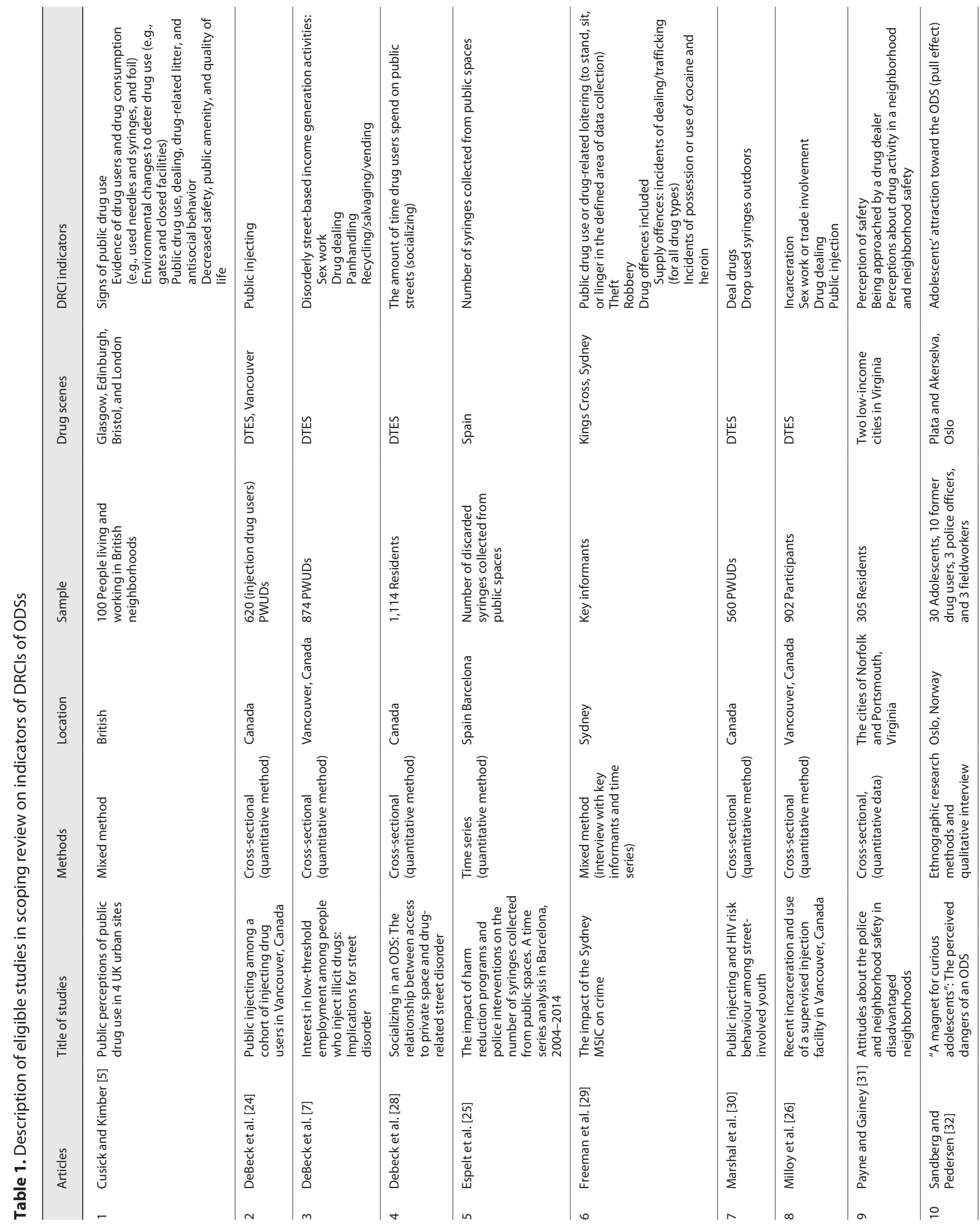




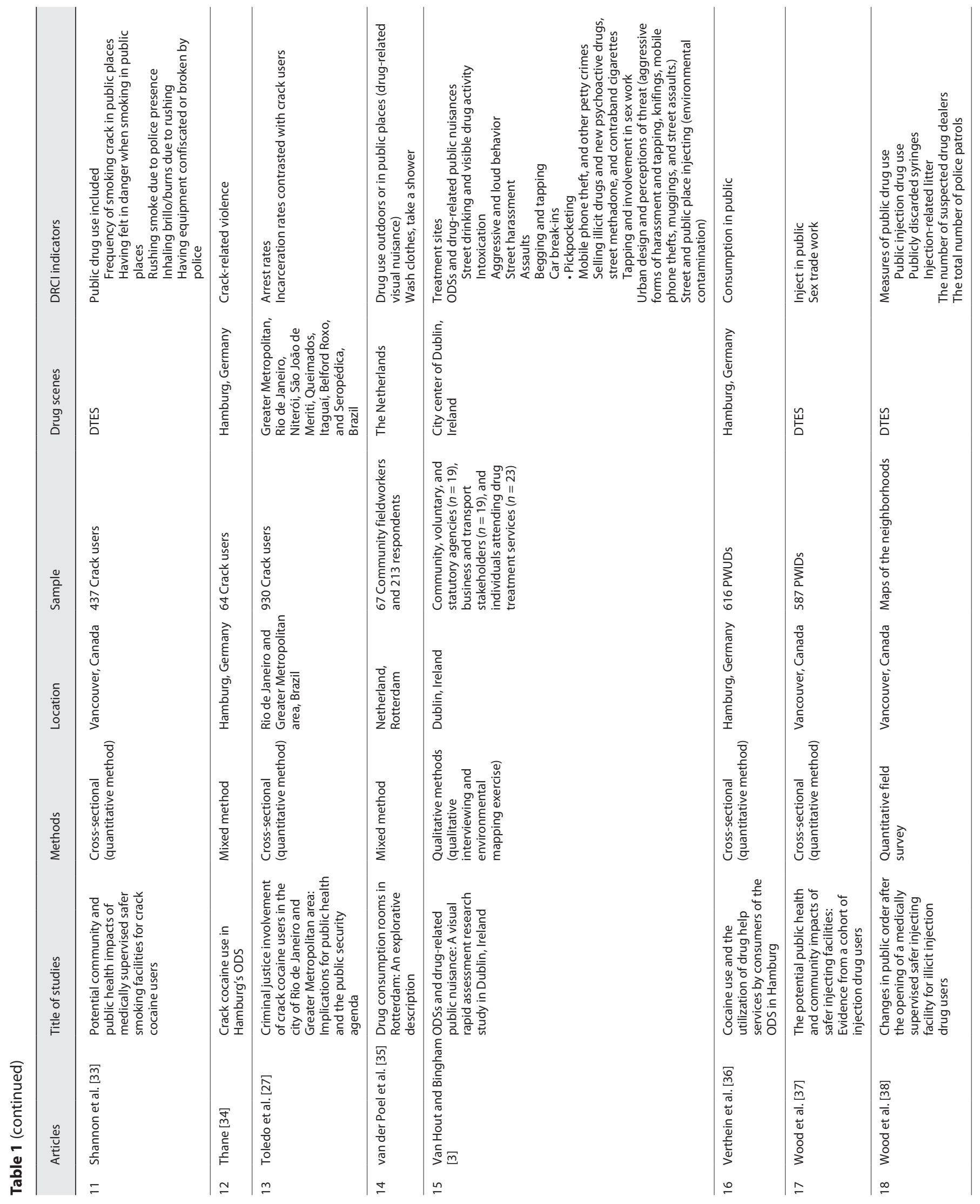

92 


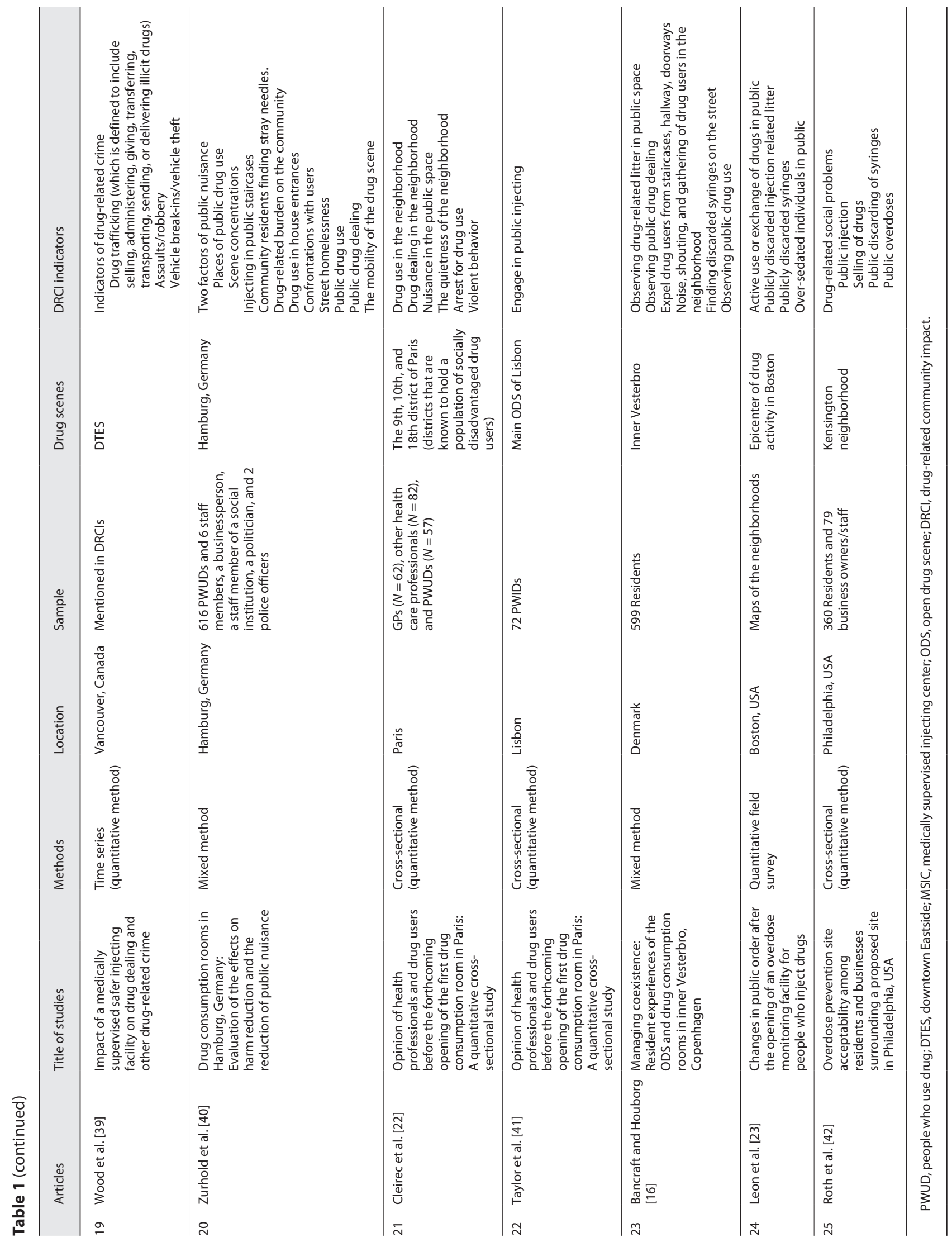


Table 2. Features of qualified studies in scoping review on DRCls of ODSs $(N=25)$

\begin{tabular}{|c|c|c|}
\hline Feature & $\begin{array}{l}\text { Studies, } \\
N\end{array}$ & $\begin{array}{l}\text { Percentage } \\
\text { of all studies }\end{array}$ \\
\hline \multicolumn{3}{|l|}{ Year of publication } \\
\hline $2001-2004$ & 6 & 24 \\
\hline $2005-2008$ & 6 & 24 \\
\hline 2009-2012 & 5 & 20 \\
\hline 2013-2017 & 3 & 12 \\
\hline $2018-2021$ & 5 & 20 \\
\hline \multicolumn{3}{|l|}{ Geographic region } \\
\hline Canada & 9 & 36 \\
\hline European countries & 11 & 44 \\
\hline Virginia/southeast of the USA & 3 & 12 \\
\hline Brazil & 1 & 4 \\
\hline Australia & 1 & 4 \\
\hline \multicolumn{3}{|l|}{ Research methods } \\
\hline Qualitative & 2 & 8 \\
\hline Quantitative & 17 & 68 \\
\hline Mixed & 6 & 24 \\
\hline \multicolumn{3}{|c|}{ Data type in quantitative and qualitative studies ${ }^{a}$} \\
\hline Time series & 2 & 8 \\
\hline Cross-sectional & 23 & 92 \\
\hline \multicolumn{3}{|l|}{ Focus of study (based on title of studies) } \\
\hline Public drug use or injection & 3 & 12 \\
\hline Crime, incarceration, and public security & & 12 \\
\hline Street disorder ${ }^{\mathrm{b}}$ & 2 & 8 \\
\hline Public perception ${ }^{c}$ & 2 & 8 \\
\hline Cocaine use in ODS & 2 & 8 \\
\hline Public nuisance & 2 & 8 \\
\hline Community impact $^{d}$ & 2 & 8 \\
\hline Syringes in public space & 1 & 4 \\
\hline Magnet of curious adolescents & 1 & 4 \\
\hline Public order ${ }^{\mathrm{e}}$ & 1 & 4 \\
\hline \multicolumn{3}{|l|}{ Drug consumption room or overdose } \\
\hline prevention site ${ }^{f}$ & 6 & 24 \\
\hline
\end{tabular}

ODS, open drug scene; $\mathrm{DRCl}$, drug-related community impact. ${ }^{a}$ Includes mixed-method studies as cross-sectional type. ${ }^{b}$ Includes disorderly street-based income generating activities and spending time on public street. ' Includes publicly drug use and neighborhood safety. ${ }^{d}$ Includes publicly drug use or injection and sex trade work. e Includes drug use in public, discarded syringes, and injectionrelated litter. ${ }^{\mathrm{f}}$ Includes indicators of drug use and deal in public, hygiene, noise, drug-related litter, and over-sedated people in public.

er articles, namely, discarded syringes in public [16, 23, $25,38,42]$; community residents finding used needles [25]; used syringes found outdoors [30], and drug or injection-related litter itself $[22,38]$. The injection-related litter was defined in more detail such as discarded syringe wrappers, syringe caps, sterile water containers, and "cookers" (containers used to heat drugs before injection).
Environmental Changes to Deter Drug Use in Public

Public perception of the negative effects of ODSs plays a crucial role in local drug and urban regeneration policies [43]. The aim of these urban regeneration strategies such as the installation of gates, CCTV, removal of facilities in parks is to deter drug use in public spaces. Cusick [43] identified these strategies as an indirect sign of drug use in public.

\section{Other Manifestations of Drug Use in Public}

Additionally reported impacts were rushing smoke due to police presence, inhaling brillo/burns due to rushing, and having equipment confiscated or broken by police (without being arrested) and police patrol all considered the manifestations of public drug use [33]. Police activities are one of the main signs of drug use in public $[38,44]$.

Definition of the Public Area of Drug Use

The definition of "public places" varied. In Cusick and Kimber's study [5], they used a comprehensive definition of public locations. The following public places of drug use were included: (1) open areas where drug use occurred such as alleyways, car parks, cars, derelict or rubbish strewn open spaces, and train stations; (2) abandoned sites like disused and seldomused parts of buildings, building sites, premises referred to as "crack houses," and squatted buildings; and (3) and accessible parts of residential or commercial property (e.g., specific houses, cafes, pubs, toilets, gardens, bushes, backyards, doorsteps, stairwells, bin shelters, and garages) [5]. In Zurhold's study [40], the public location of drug use was investigated through "main places of drug use" by asking 616 drug users in the Hamburg drug scene about the locations where they had used drugs during the past $24 \mathrm{~h}$. One-third of the respondents stated having taken drugs outdoors including parks, subways or railway stations, house entryways and stairways, and the vicinity of a consumption room [40]. In other studies, they defined public areas in less detail such as public lavatories, streets, alleys, parks or public gardens, abandoned buildings, parking lots, and other public settings [24, 25, 33] and lack of specific definition in the remaining studies [16, $22,23,28-30,35,38,41,42]$.

\section{Drug Dealing}

DRCIs are caused not only by drug use in public but also by activities such as drug dealing in/around the ODSs. In some studies, the effects of establishing a medi-
Eur Addict Res 2022;28:87-102 DOI: $10.1159 / 000519886$
Saberi Zafarghandi/Eshrati/Rashedi/ Vameghi/Arezoomandan/Clausen/Waal 
Table 3. Features of study purposes in scoping review on DRCls of ODSs

\begin{tabular}{|c|c|c|}
\hline Feature & $\begin{array}{l}\text { Studies, } \\
N\end{array}$ & $\begin{array}{l}\text { Percentage } \\
\text { of all } \\
\text { studies }\end{array}$ \\
\hline $\begin{array}{l}\text { Effect of medically supervised SIFs or SSFs on } \\
\text { Crime and loitering } \\
\text { Incarceration, sex trade work, drug dealing, and public injection } \\
\text { Publicly drug use } \\
\text { Community impact } \\
\text { Public order } \\
\text { Crime rate }\end{array}$ & 6 & 24 \\
\hline $\begin{array}{l}\text { Effect of overdose prevention site on } \\
\text { Publicly drug use or injection } \\
\text { Drug dealing in public } \\
\text { Over-sedated people in public } \\
\text { Discarded paraphernalia in public }\end{array}$ & 2 & 8 \\
\hline $\begin{array}{l}\text { Effect of CRs on } \\
\text { Visual nuisance } \\
\text { Public nuisance } \\
\text { Drug use or injection in public } \\
\text { Publicly drug dealing } \\
\text { Drug-related litter } \\
\text { Noise, shouting, violence, and tranquility in neighborhood } \\
\text { Arrest }\end{array}$ & 5 & 20 \\
\hline $\begin{array}{l}\text { Interventions targeted in ODSs and } \\
\text { Public injecting } \\
\text { Discarded syringes collected from the public space }\end{array}$ & 2 & 8 \\
\hline $\begin{array}{l}\text { Perception of } \\
\text { Unsafety to be confronted by public drug use }\end{array}$ & & \\
\hline $\begin{array}{l}\text { Unsafety to be approached by a drug dealer } \\
\text { Unsafety for visibility of DRCls }\end{array}$ & 3 & 12 \\
\hline $\begin{array}{l}\text { Disorderly street-based income generating practices and preferred } \\
\text { alternative work if possible }\end{array}$ & 1 & 4 \\
\hline $\begin{array}{l}\text { ODSs and start drug use by curios city-dwelling adolescents } \\
\text { Crack users in ODS and }\end{array}$ & 1 & 4 \\
\hline $\begin{array}{l}\text { Attitude toward drug } \\
\text { Arrest and imprisonment }\end{array}$ & 2 & 8 \\
\hline Patterns of drug use in ODSs & 1 & 4 \\
\hline $\begin{array}{l}\text { Socializing (time spending in public) of PWUDs in ODSs and preferred } \\
\text { private spaces if possible }\end{array}$ & $\begin{array}{l}1 \\
1\end{array}$ & $\begin{array}{l}4 \\
4\end{array}$ \\
\hline
\end{tabular}

SIF, safer injecting facilities; ODS, open drug scene; DRCl, drug-related community impact; SSFs, safer smoking facilities; CR, consumption rooms; PWUDs, people who use drugs. cally supervised safer injecting facility on the reduction of the number of suspected drug dealers and arrest for drug use has been considered as an indicator of the magnitude of the public disorder $[5,16,22,23,38,39,42]$. In the included studies, drug dealing has been considered as a source of street-based income generation for drug users [7], insecurity feelings in people who are close to drug dealing [31], a type of drug-related crime [29], or as a factor of DRCIs in ODSs [40].

Drug Scene-Related Community Impacts
Crime, Incarceration, and Arrest

In some countries such as Australia, Canada, and some European countries, establishing safer injection facilities (SIFs) was a solution for the reduction of social impacts of ODSs [22, 38]. Milloy et al. [45] and Cleirec et al. [22] investigated the effect of SIFs on incarceration rates of PWUDs. Incarceration is a common experience among PWUDs in this area because of the high cost of illicit drugs, lack of legal income sources opportunities, and criminalization of substance use disorder $[5,26,46]$. In 
Table 4. Frequency of DRCl indicators in eligible quantitative and mixed method studies

\begin{tabular}{lll}
\hline Indicators of DRCls & $\begin{array}{l}\text { Studies, } \\
\text { Percentage } \\
\text { of all } \\
\text { studies }\end{array}$ \\
\hline $\begin{array}{l}\text { Signs of public drug use } \\
\quad \text { Public drug use }\end{array}$ & 13 & 52 \\
$\quad$ Drug related litter & 8 & 32 \\
Environmental changes to deter drug use & 1 & 4 \\
Other sings & 1 & 4 \\
$\quad$ Smoke in rush due to police presence & 1 & 4 \\
$\quad$ Inhaling brillo/burns due to rushing & 1 & 4 \\
$\quad$ Having equipment confiscated or broken by police & 1 & 4 \\
$\quad$ Police patrol & 11 & 44 \\
Drug dealing & 5 & 20 \\
Crime, incarceration, and arrest & & 12 \\
Disorderly street-based income generating practices & 3 & 1 \\
Sex work trade & 1 & 4 \\
Panhandling & 1 & 4 \\
Squeegeeing & 1 & 4 \\
Recycling/salvaging/vending & 6 & 24 \\
Drug-related loitering & 2 & 8 \\
Noise, violence, and tranquility of the neighborhood & 2 & 8 \\
Perception of safety & & \\
\hline
\end{tabular}

DRCl, drug-related community impact. some studies, incarceration or arrest generally has been considered as a marker of public disorder implication or community concern in terms of DRCIs $[5,27]$. In some other studies, crimes have been investigated in more detail including acquisitive crimes (such as robbery, theft, and car break-in) and drug-related crimes (such as dealing/trafficking of illicit drugs, possession or use of cocaine and heroin in/around ODSs) [29, 39].

\section{Street-Based Income Generation Practices}

Street-based income generation activities were assessed through income sources such as sex work trade, drug dealing, panhandling, squeegeeing, and recycling/ salvaging/vending (including salvaging recyclable materials and unpermitted street vending). These activities were considered street-based because they were concentrated on locations known as ODSs which were recognizable in urban areas such as Downtown Eastside, Canada [7]. Additionally, the community perceived these activities as undesirable [44].

In addition, some disorderly income generation activities have variable definitions. For example, sex trade work is included as a disorderly street-based income generation activity [7], crime [5], and risky behavior [37]. Furthermore, as mentioned before, drug dealing was con- sidered as a drug offense $[5,29,39]$, disorderly income generation practice [7], and as a public nuisance [40].

\section{Drug-Related Loitering}

Spending time on the street every day for socializing or simply stand, sit, and linger by PWUDs or dealers in/ around the ODSs is described as an example of drug-related public harm $[28,29]$. Loitering in public areas has a negative impact on business and surrounding communities and reduces the pleasure from public places for the general public [43]. Drug-related loitering may be caused by limited access to private space [28]. A study found the effect of the establishment of medically supervised injecting center in loitering of local PWUDs around the center without the influx of new drug users and dealers to the district [29]. Some studies with overdose crises in their areas such as Kensington, and Boston, USA, considered over-sedated people in public whose level of consciousness was low as a concern. Described community responses were to expel drug users from doorways or hallways in the neighborhood [23, 42].

\section{Perception of Safety}

Decreased safety, public amenity, and quality of life were noted as a consequence of the social impact of ODSs
Saberi Zafarghandi/Eshrati/Rashedi/ Vameghi/Arezoomandan/Clausen/Waal 
Table 5. Extracted codes of DRCl indicators in qualitative studies and qualitative part of mixed studies

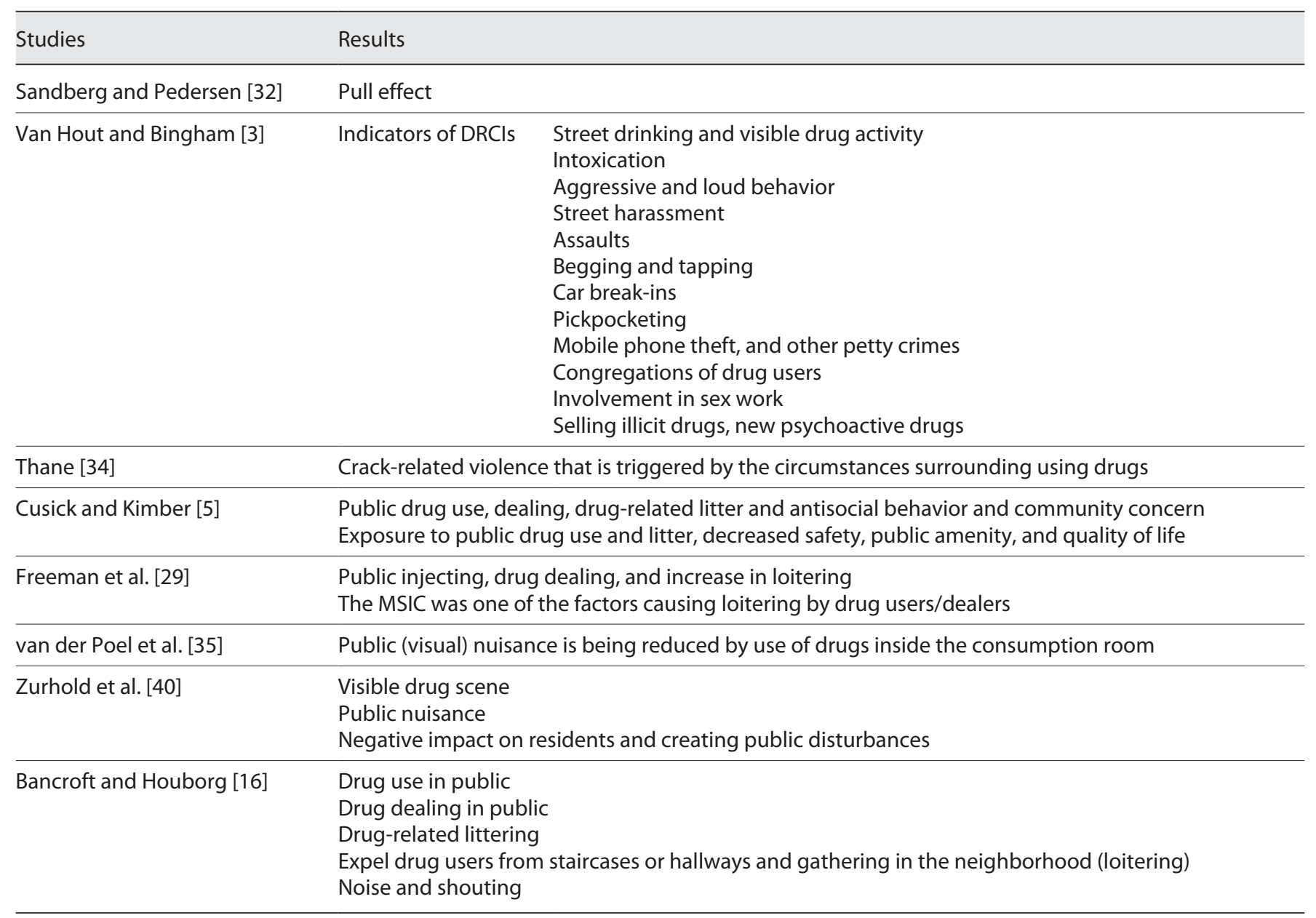

DRCl, drug-related community impact; MSIC, medically supervised injecting center.

[43]. Life in a crime-prone area involves hearing about crime and victimization; being approached by a drug dealer; social exposure to public drug use and litter, drug dealing and antisocial behavior, and perceptions about drug activity in a neighborhood resulting in negative impacts on the perception of safety [31].

Noise

Noise, shouting, violent behavior, and tranquility of the neighborhood were addressed as a drug scene-related problem that would be influenced by opening a drug consumption room as a pragmatic solution [16, 22]. With a lens of urban sociology, drug consumption rooms are considered an environmental intervention to remove DRCIs of drug scenes [16]. In another study, aggression, loud behavior, street harassment, and as- saults were considered a drug-related public nuisance [3].

\section{Indicators Identified in Qualitative Studies}

As Table 5 illustrates, in addition to the indicators of DRCIs in quantitative studies, some studies considered extra specific behaviors as DRCIs, such as pull effect, drinking alcohol, antisocial behavior, general community concerns, and drug circumstance-related violence [29, 32, 34, 43]. In some other studies, the role of exposure to drug-related public nuisance has been investigated qualitatively and some specific indicators such as street drinking and visible drug activity were reported $[3,35,40]$. Some results are inconsistent. For example, one study did not find the pull effects of ODSs as a problem because the scene did not attract city-dwelling adolescents to ODSs [32]. 


\section{Discussion}

DRCI indicators are heterogeneous and are affected by several factors. These factors include social awareness, political discourse, and historical approaches to dealing with and using drugs. Some societies have a strict strategy, while others have accepted harm reduction policies. The main classification of DRCI indicators were drug use in public view, discarded paraphernalia in public, drug dealing, drug-related loitering, crime and incarceration, street-based income generation activities, the experience of unsafety by the general public, and noise.

\section{Direct and Indirect Indicators}

Some identified indicators in the current study partly overlapped with indicators that have been previously reported by the EMCDDA and Pompidou group. Some DRCI indicators are not presented in the current study including poverty, street homelessness, the emergence of crack houses, attraction of new people to drug scene, and mental illness [2, 4, 47]. However, some indicators including street dealing, crime, discarded injecting equipment, and intimidation of citizens were common in previous reports and current studies [2, 4, 47]. Therefore, for arranging the indicators, they can potentially be categorized into direct and indirect indicators of DRCIs. Direct indicators are the common indicators in the peer-reviewed articles and EMCDDA and Pompidou group reports, whereas indirect indicators are the ones that were mentioned in the reports $[2,48]$.

The major features of ODSs including drug dealing and/or taking in public, are examples of direct indicators of DRCIs [1]. Some PWUDs reside around/in the drug scenes due to the availability of the drug dealers [47], whereas some others move to these areas to purchase drugs $[47,49]$. Some PWUDs may consume drugs in/ around the scene due to strong craving or few alternative (and/or safe) places to use drugs, such as SIFs [28, 50-52]. Another negative impact of public drug use is the disposal of drug paraphernalia in public spaces [43]. Additionally, PWUDs have to move around the neighborhood while intoxicated if they utilize the drug scene to use drugs. Therefore, PWUDs might be arrested by the police due to criminalization of drug use and possession in most countries $[53,54]$. Also, local residents and businesses who share the same public space as the ODSs may experience reduced safety and public amenity $[31,43]$.

It is noteworthy that most of the ODSs are concentrated in the disadvantaged areas of societies. In disadvantaged areas of societies, in addition to drug-using and dealing, other factors such as higher rates of homelessness, poverty, disturbing behaviors, or mental illness are common. These factors often are perceived as DRCIs. However, these factors do not have a direct association with ODSs [55]. For example, in a study, Small et al. [55] showed that public drug use often occurs in unsanitary and unhygienic spaces because of ecological features of Vancouver public injecting settings. Vancouver's drug scenes are concentrated in a place where low-cost housing, high levels of mental illness, and homelessness are common $[31,55,56]$, and historically, the congregation of drug-related disorders is one of the features of these areas [57]. Also, research showed that public drug injection is common in deprived areas and among homeless people as a distractor to assist them in sleeping and deal with cold weather $[28,50,58]$. Both direct and indirect indicators of DRCIs are likely important in forming of experience or perception of DRCIs by population around ODSs. The interventions to deal with the issues related to direct and indirect indicators will be different.

\section{The Role of Perception}

Some studies have investigated community perceptions of safety, in terms of proximity to drug dealers, exposure to drug use, city-dwelling adolescents' perception about hazards of drug scenes, and perceived effects of drug consumption rooms in the surrounding areas [5,22, $31,32,40]$. Communities vary in the way they define and tolerate public disturbances around drug scenes, and the related interventions [8]. The studies have indicated multidimensional and context-specific characteristics of DRCI indicators.

However, drug scenes are likely identified as "no go" areas, and the dynamics between residents and business owners/workers, and the ODSs affect the perception of the problem among the general public in a negative way. The studies that focused on drug scene-related nuisances tend to have an assumption that drug scene-related practices are a nuisance $[3,5]$. While in other studies that neutrally and broadly focused on the experiences of residents about drug scenes or related interventions such as drug consumption rooms, residents have supportive perspectives and acceptability of a drug scene in the neighborhood and related interventions [16]. Also, in a study, citydwelling adolescents perceived drug scenes as a dangerous place; hence, they were not attracted to the drug scene, while other stockholders considered drug scenes as a place attracting vulnerable people [32]. Therefore, the presumption and different experiences about ODSs may be related to variations in perception of behavior, activity, or situation as DRCIs $[1,5,31]$.
Saberi Zafarghandi/Eshrati/Rashedi/ Vameghi/Arezoomandan/Clausen/Waal 
The Role of Harm Reduction Facilities

One topic which is addressed in the literature of DRCIs is the provision of harm reduction interventions like drug consumption rooms which are also referred to as overdose prevention sites, safe injection facilities, and medically supervised injection or smoking rooms $[16,33$, $39,42,45]$. Such facilities, in addition to direct harm reduction for health outcomes, may also positively impact DRCI indicators such as the level of drug-related litter, drug use in public, and the frequency and intensity of drug-related or acquisition crime around the facilities $[59,60]$. For example, evaluations of supervised consumption rooms showed that the implementation of these facilities resulted in not only reduced drug use in public and drug-related or acquisitive crimes $[5,29,61]$ but also improved local surroundings and public order issues [5]. In addition, disposal of drug-related paraphernalia around the facilities and the ODSs significantly decreased [25, 62-64].

Despite the numerous health and social benefits of SIFs, it is only a limited number of communities in some high-income countries such as European cities, Canada, and recently the USA that have implemented SIFs. In many societies, regulations regarding use of illicit substances, the socio-structural contexts such as stigma, and social norms are barriers to implementing such public health interventions [59, 65-67]. Although drug scenes exist in most countries, research about drug scenes has probably not been a priority for low- to middle-income countries. Therefore, the lack of published research does not mean the lack of drug scenes and their social consequences in low- to middle-income countries.

\section{Timeline of the Current Studies}

DRCIs are not a new phenomenon. According to the studies, during the recent 3 decades, there were growing concerns over DRCIs related to ODSs that are located in an increasing number of public areas and geographical regions.

More recent studies focused on the development of specific interventions to tackle these community challenges. The findings indicate some sort of "progress along a timeline" in the types of studies. The first publications typically describe and identify characteristics of ODSs in a given setting [1]. More recent studies describe and evaluate the related interventions [23]. As a result, communities with more recent concerns about DRCIs can now find not only published results on DRCI descriptions, but also on interventions and their efficacy. Therefore, societies with recent concern about DRCIs, in addition to their current local interventions, can rapidly be in a position to adapt their interventions to measures with proven effectiveness. For example, from Canada, the published studies include a range of interventions, aiming at different indicators of DRCIs; where interventions such as SIFs addressed direct DRCI indicators such as drug use in public, while other interventions have focused on more indirect indicators of DRCIs such as access of homeless drug users to low threshold housing and employment facilities [7, 28].

\section{The Interaction between DRCI Indicators}

The indicators of DRCI can influence and reinforce each other. It is most commonly reported that drug use in public is caused by the lack of supportive housing, which in turn has led to the loitering among PWUDs [24, $68,69]$. PWUDs encounter some barriers in access to housing facilities due to their economic issues and the level of tolerance of homeowners [70]. Consequently, loitering and drug use in public are frequently concentrated in deprived areas. Besides, the relationship between income-generating criminal activities like drug dealing, robbery and theft, and drug use is well established because of the legal prohibitions against drug use, the high cost of illicit drugs, and the lack of opportunities for legal income generation practices $[5,29,46]$. The criminalization of drug use has resulted in incarceration for around half of PWUDs [5, 71]. Similarly, recent incarceration was found to be associated with injection in public and smoking heroin frequently, unstable housing, and drug dealing [5].

In addition, drug use in public is responsible for the unsafe disposal of syringes [25]. In fact, discarded paraphernalia such as syringes reflect recent drug use and are often found in streets or parks around ODSs [62-64, 72] and may well be seen as a result of lacking alternative safe drug-taking spaces. So, as mentioned before, the indicators of DRCIs might interact with each other because of multiple factors that are not only related to individual behaviors of PWUDs but also the societal structures [73].

This is likely the first scoping review of international literature on DRCI indicators. The review had broad inclusion criteria and was not limited to one indicator of DRCIs or one set of research methodologies. We could not access the PsycINFO database during the period of the review. We did not search interventions that addressed DRCIs separately. In addition, it is difficult to make comprehensive classifications of DRCIs without considering the national policies and tolerance level of issues related to drug use within a country's wider policy system. As a 
consequence, we just classified more frequent ( $>2$ times mentioned in the literature) DRCI indicators in order to have the main overview of the published social problems of ODSs. However, there are some specific DRCI indicators in specific settings which need more research.

In the current review, we focused on specific outcomes for the wider community around, but not involved in, ODSs. So, we did not review specific social problems of ODSs for people who are involved in ODSs such as gendered violence for women who utilize/form part of scenes [74] or limited access to health and social services because of police raids and restrictions in these areas [75]. The interpretation of the results is also limited by the limitations of every included study. Most studies were from high-income countries that their experiences may not always generalize to middle- to low-income countries. Also, most studies only collected data at baseline or certain time points. It is possible that changes in time-dependent indicators such as drug using or dealing in public in the period of or after the policy interventions such as crack-down policing were missed. There were numerous approaches to measure community impacts. For example, surveys, qualitative interviews, and focus groups with local key informants and relevant city workers or local drug users, official statistics, and social and direct observation have all been used in studies of community impacts which have their limitations.

\section{Conclusion}

Due to the diversity and the extent of drug use and deal, social awareness, political discourse, and historical approaches to dealing and using drug, the elimination of the phenomenon of ODSs can be challenging in any country. To manage the ODS phenomenon, we need to determine DRCI indicators. By improving the indicators, we can reduce most of the drug scene-related problems. The indicators of DRCIs interplay and reinforce each other. In addition, the indicators are mainly concentrated in areas where unsanitary spaces, poverty, homelessness, disturbing behaviors, and mental illness are common. So, as Rhodes has assumed, to respond to indicators of DRCIs, focusing on structural, environmental, and social conditions will be a better way to improve them. Also, given the role of perception and tolerance of drug issues, and drug-related laws, it seems that in addition to law enforcement measures, community-based interventions involving residents of disadvantaged areas are needed to promote innovative interventions.

\section{Acknowledgments}

The authors thank Miss Eskandari, Miss Hege Kornor, and Miss Ingrid Harboe for finding the search terms and for the process of finding articles in databases.

\section{Statement of Ethics}

The ethical approval was obtained from the Ethics Committee of Iran University of Medical Sciences, Iran (IR-IUMS. REC. 1398.693).

\section{Conflict of Interest Statement}

Helge Waal is an editorial board member of this journal. The other authors have no conflicts of interest to declare.

\section{Funding Sources}

The article is a part of a study funded by the Iran University of Medical Sciences (98-2-50-15287).

\section{Author Contributions}

All authors collaboratively generated the research question and overall research design. V.R. and S.E. conducted coding. The authors revised and discussed the codes throughout the analysis. All authors provided the final approval of the manuscript.

\section{Data Availability Statement}

All data generated or analyzed during this study are included in this article. Further inquiries can be directed to the corresponding author.

References

1 Bless R, Korf DJ, Freeman M. Open drug scenes: a cross-national comparison of concepts and urban strategies. Eur Addict Res. 1995; 1(3):128-38.

2 Connoly J. Responding to open drug scenes and drug-related crime and public nuisance: towards a partnership approach. Citeseer; 2006.

3 Van Hout MC, Bingham T. Open drug scenes and drug-related public nuisance: a visual rapid assessment research study in Dublin, Ireland. J Ethn Subst Abuse. 2013;12(2):15478.

4 European Monitoring Centre for Drugs and Drug Addiction. Annual report: selected issues. Office for Official Publications of the European Communities; 2006. 
5 Cusick L, Kimber J. Public perceptions of public drug use in four UK urban sites. Int J Drug Policy. 2007;18(1):10-7.

6 Zafarghandi MBS, Eshrati S, Vameghi M, Ranjbar H, Arezoomandan R, Clausen T, et al. Drug-related community issues and the required interventions in open drug scenes in Tehran, Iran: a qualitative study protocol. BMJ Open. 2019;9(10):e030488.

7 DeBeck K, Wood E, Qi J, Fu E, McArthur D, Montaner J, et al. Interest in low-threshold employment among people who inject illicit drugs: implications for street disorder. Int $\mathrm{J}$ Drug Policy. 2011;22(5):376-84.

8 Waal H, Clausen T, Gjersing L, Gossop M. Open drug scenes: responses of five European cities. BMC Public Health. 2014;14(1):85312.

9 Waal H, Gjersing L, Clausen T. Open drug scenes and overdose mortality-what to do. Oslo, Norway: Senter for Rus-og Avhengighetsforskning (SERAF); 2011.

10 Munn Z, Peters MDJ, Stern C, Tufanaru C, McArthur A, Aromataris E. Systematic review or scoping review? Guidance for authors when choosing between a systematic or scoping review approach. BMC Med Res Methodol. 2018;18(1):143-7.

11 Grant MJ, Booth A. A typology of reviews: an analysis of 14 review types and associated methodologies. Health Info Libr J. 2009; 26(2):91-108.

12 Peters MD, Godfrey CM, Khalil H, McInerney P, Parker D, Soares CB. Guidance for conducting systematic scoping reviews. Int J Evid Based Healthc. 2015;13(3):141-6.

13 Arksey H, O'Malley L. Scoping studies: towards a methodological framework. Int J Soc Res Methodol. 2005;8(1):19-32.

14 Tricco AC, Lillie E, Zarin W, O'Brien KK, Colquhoun $\mathrm{H}$, Levac D, et al. PRISMA extension for scoping reviews (PRISMA-ScR): checklist and explanation. Ann Intern Med. 2018;169(7):467-73.

15 Magwood O, Salvalaggio G, Beder M, Kendall C, Kpade V, Daghmach W, et al. The effectiveness of substance use interventions for homeless and vulnerably housed persons: a systematic review of systematic reviews on supervised consumption facilities, managed alcohol programs, and pharmacological agents for opioid use disorder. PLoS One. 2020; 15(1):e0227298.

16 Bancroft M, Houborg E. Managing coexistence: resident experiences of the open drug scene and drug consumption rooms in inner Vesterbro, Copenhagen. Contemp Drug Probl. 2020;47(3):210-30.

17 Schlosser RW, Wendt O, Bhavnani S, NailChiwetalu B. Use of information-seeking strategies for developing systematic reviews and engaging in evidence-based practice: the application of traditional and comprehensive Pearl Growing. A review. Int J Lang Commun Disord. 2006;41(5):567-82.
18 Sanderson S, Tatt ID, Higgins JP. Tools for assessing quality and susceptibility to bias in observational studies in epidemiology: a systematic review and annotated bibliography. Int J Epidemiol. 2007;36(3):666-76.

19 Downes MJ, Brennan ML, Williams HC, Dean RS. Development of a critical appraisal tool to assess the quality of cross-sectional studies (AXIS). BMJ Open. 2016;6(12): e011458.

20 Harden A, Brunton G, Fletcher A, Oakley A. Teenage pregnancy and social disadvantage: systematic review integrating controlled trials and qualitative studies. BMJ. 2009;339:b4254.

21 Bromley H, Dockery G, Fanton C, Nhlema B, Smith H, Tolhurst R, et al. Criteria for evaluating qualitative studies: developed by the Qualitative Research and Health Working Group LSTM. 2002. Available from: https:// wwwdeptsttuedu/education/ourpeople/Faculty/additional_pages/duemer/epsy_5382_ class materials/Evaluating-Qualitative-Studiespdf.

22 Cleirec G, Fortias M, Bloch V, Clergue-Duval V, Bellivier F, Dusouchet T, et al. Opinion of health professionals and drug users before the forthcoming opening of the first drug consumption room in Paris: a quantitative crosssectional study. Harm Reduct J. 2018;15(1): 53.

23 León C, Cardoso LJP, Johnston S, Mackin S, Bock B, Gaeta JM. Changes in public order after the opening of an overdose monitoring facility for people who inject drugs. Int J Drug Policy. 2018;53:90-5.

24 DeBeck K, Small W, Wood E, Li K, Montaner J, Kerr T. Public injecting among a cohort of injecting drug users in Vancouver, Canada. J Epidemiol Community Health. 2009;63(1): 81-6.

25 Espelt A, Villalbí J, Bosque-Prous M, ParésBadell O, Mari-Dell'Olmo M, Brugal M. The impact of harm reduction programs and police interventions on the number of syringes collected from public spaces. A time series analysis in Barcelona, 2004-2014. Int J Drug Policy. 2017;50:11-8.

26 Milloy MJ, Wood E, Small W, Tyndall M, Lai $\mathrm{C}$, Montaner J, et al. Incarceration experiences in a cohort of active injection drug users. Drug Alcohol Rev. 2008;27(6):693-9.

27 Toledo L, Cano I, Bastos L, Bertoni N, Bastos FI. Criminal justice involvement of Crack cocaine users in the city of Rio de Janeiro and Greater Metropolitan area: implications for public health and the public security agenda. Int J Drug Policy. 2017;49:65-72.

28 DeBeck K, Wood E, Qi J, Fu E, McArthur D, Montaner J, et al. Socializing in an open drug scene: the relationship between access to private space and drug-related street disorder. Drug Alcohol Depend. 2012;120(1-3):28-34.

29 Freeman K, Jones CG, Weatherburn DJ, Rutter S, Spooner CJ, Donnelly N. The impact of the Sydney medically supervised injecting centre (MSIC) on crime. Drug Alcohol Rev. 2005;24(2):173-84.
30 Marshall BD, Kerr T, Qi J, Montaner JS, Wood E. Public injecting and HIV risk behaviour among street-involved youth. Drug Alcohol Depend. 2010;110(3):254-8.

31 Payne BK, Gainey RR. Attitudes about the police and neighborhood safety in disadvantaged neighborhoods: the influence of criminal victimization and perceptions of a drug problem. Crim Justice Rev. 2007;32(2):14255.

32 Sandberg S, Pedersen W. "A magnet for curious adolescents": the perceived dangers of an open drug scene. Int J Drug Policy. 2008; 19(6):459-66.

33 Shannon K, Ishida T, Morgan R, Bear A, Oleson M, Kerr T, et al. Potential community and public health impacts of medically supervised safer smoking facilities for crack cocaine users. Harm Reduct J. 2006;3(1):1-8.

34 Thane K. Crack cocaine use in Hamburg's open drug scene. J Drug Issues. 2002;32(2): 423-30.

35 van der Poel A, Barendregt C, van de Mheen D. Drug consumption rooms in Rotterdam: an explorative description. Eur Addict Res. 2003;9(2):94-100.

36 Verthein U, Haasen C, Prinzleve M, Degkwitz $\mathrm{P}$, Krausz M. Cocaine use and the utilisation of drug help services by consumers of the open drug scene in Hamburg. Eur Addict Res. 2001;7(4):176-83.

37 Wood E, Kerr T, Spittal PM, Li K, Small W, Tyndall MW, et al. The potential public health and community impacts of safer injecting facilities: evidence from a cohort of injection drug users. J Acquir Immune Defic Syndr. 2003;32(1):2-8.

38 Wood E, Kerr T, Small W, Li K, Marsh DC, Montaner JS, et al. Changes in public order after the opening of a medically supervised safer injecting facility for illicit injection drug users. CMAJ. 2004;171(7):731-4.

39 Wood E, Tyndall MW, Lai C, Montaner JS, Kerr T. Impact of a medically supervised safer injecting facility on drug dealing and other drug-related crime. Subst Abuse Treat Prev Policy. 2006;1:13.

40 Zurhold H, Degkwitz P, Verthein U, Haasen C. Drug consumption rooms in Hamburg, Germany: evaluation of the effects on harm reduction and the reduction of public nuisance. J Drug Issues. 2003;33(3):663-88.

41 Taylor H, Curado A, Tavares J, Oliveira M, Gautier D, Maria JS. Prospective client survey and participatory process ahead of opening a mobile drug consumption room in Lisbon. Harm Reduct J. 2019;16(1):49-7.

42 Roth AM, Kral AH, Mitchell A, Mukherjee R, Davidson P, Lankenau SE. Overdose prevention site acceptability among residents and businesses surrounding a proposed site in Philadelphia, USA. J Urban Health. 2019; 96(3):341-52.

43 Cusick L. Drug consumption rooms and regeneration: environmental solutions to social problems. Int J Drug Policy. 2007;18:10-7. 
44 Kerr T, Small W, Johnston C, Li K, Montaner JS, Wood E. Characteristics of injection drug users who participate in drug dealing: implications for drug policy. J Psychoactive Drugs. 2008;40(2):147-52.

45 Milloy M-J, Wood E, Tyndall M, Lai C, Montaner J, Kerr T. Recent incarceration and use of a supervised injection facility in Vancouver, Canada. Addict Res Theory. 2009;17(5): 538-45.

46 DeBeck K, Shannon K, Wood E, Li K, Montaner J, Kerr T. Income generating activities of people who inject drugs. Drug Alcohol Depend. 2007;91(1):50-6.

47 Hayashi K, Ti L, Dong H, Bingham B, Day A, Joe R, et al. Moving into an urban drug scene among people who use drugs in Vancouver, Canada: latent class growth analysis. PLoS One. 2019;14(11):e0224993.

48 European Monitoring Centre for Drugs and Drug Addiction. Perspectives on drugs: drug consumption rooms: an overview of provision and evidence. Luxembourg: Office for Official Publications of the European Communities; 2017.

49 Fast D, Shoveller J, Shannon K, Kerr T. Safety and danger in downtown Vancouver: understandings of place among young people entrenched in an urban drug scene. Health Place. 2010;16(1):51-60.

50 Stevenson B. Research into the nature and size of public drug injecting in Glasgow city. Glasgow, Scotland: NHS Greater Glasgow and Clyde; 2010.

51 Hunt N, Lloyd C, Kimber J, Tompkins C. Public injecting among UK needle and syringe programme (NSP) attendees and willingness to use a drug consumption room. Int J Drug Policy. 2007;18(1):62-5.

52 de la Fuente L, Bravo MJ, Toro C, Brugal MT, Barrio G, Soriano V, et al. Injecting and HIV prevalence among young heroin users in three Spanish cities and their association with the delayed implementation of harm reduction programmes. J Epidemiol Community Health. 2006;60(6):537-42.

53 DeBeck K, Cheng T, Montaner JS, Beyrer C, Elliott R, Sherman S, et al. HIV and the criminalisation of drug use among people who inject drugs: a systematic review. Lancet HIV. 2017;4(8):e357-74.
54 Pollini RA, Brouwer KC, Lozada RM, Ramos R, Cruz MF, Magis-Rodriguez C, et al. Syringe possession arrests are associated with receptive syringe sharing in two Mexico-US border cities. Addiction. 2008;103(1):101-8.

55 Small W, Rhodes T, Wood E, Kerr T. Public injection settings in Vancouver: physical environment, social context and risk. Int J Drug Policy. 2007;18(1):27-36.

56 Knight KR, Lopez AM, Comfort M, Shumway M, Cohen J, Riley ED. Single room occupancy (SRO) hotels as mental health risk environments among impoverished women: the intersection of policy, drug use, trauma, and urban space. Int J Drug Policy. 2014;25(3):556-61.

57 Kerr T, Wood E, Palepu A, Wilson D, Schechter MT, Tyndall MW. Responding to an explosive HIV epidemic driven by frequent cocaine injection: Is there a role for safe injecting facilities? J Drug Issues. 2003;33(3): 579-608.

58 Neale J, Tompkins C, Sheard L. Barriers to accessing generic health and social care services: a qualitative study of injecting drug users. Health Soc Care Community. 2008;16(2): 147-54.

59 Bardwell G, Strike C, Altenberg J, Barnaby L, Kerr T. Implementation contexts and the impact of policing on access to supervised consumption services in Toronto, Canada: a qualitative comparative analysis. Harm Reduct J. 2019;16(1):30-9.

60 Behrends CN, Paone D, Nolan ML, Tuazon E, Murphy SM, Kapadia SN, et al. Estimated impact of supervised injection facilities on overdose fatalities and healthcare costs in New York City. J Subst Abuse Treat. 2019;106:7988.

61 Hedrich D. European report on drug consumption rooms. European Monitoring Centre for Drugs and Drug Addiction; 2004.

62 Wood E, Tyndall MW, Montaner JS, Kerr T. Summary of findings from the evaluation of a pilot medically supervised safer injecting facility. CMAJ. 2006;175(11):1399-404.

63 De Montigny L, Vernez Moudon A, Leigh B, Kim SY, Young K. Assessing a drop box programme: a spatial analysis of discarded needles. Int J Drug Policy. 2010;21(3):208-14.

64 Vecino C, Villalbí JR, Guitart A, Espelt A, Bartroli M, Castellano Y, et al. Safe injection rooms and police crackdowns in areas with heavy drug dealing. Evaluation by counting discarded syringes collected from the public space. Adicciones. 2013;25(4):333-8. Spanish.

65 Pfadenhauer LM, Gerhardus A, Mozygemba K, Lysdahl KB, Booth A, Hofmann B, et al. Making sense of complexity in context and implementation: the context and implementation of complex interventions (CICI) framework. Implement Sci. 2017;12(1):21.

66 Schatz E, Nougier M. Drug consumption rooms: evidence and practice. London: International Drug Policy Consortium; 2012.

67 Rhodes T, Hedrich D. Harm reduction: evidence, impacts and challenges. Office for Official Publications of the European Communities; 2010.

68 Scheim A, Rachlis B, Bardwell G, Mitra S, Kerr T. Public drug injecting in London, Ontario: a cross-sectional survey. CMAJ Open. 2017;5(2):E290.

69 Missed opportunities in the establishment of safer injection facilities: reviewing the evidence to date. In: Kerr T, Tyndall M, Montaner J, Wood E, editors. 15th International Conference on the Reduction of Drug Related Harm; 2004. confpap.

70 Evans L, Strathdee SA. A roof is not enough: unstable housing, vulnerability to HIV infection and the plight of the SRO. Int J Drug Policy. 2006;17(2):115-7.

71 Macalino GE, Vlahov D, Sanford-Colby S, Patel S, Sabin K, Salas C, et al. Prevalence and incidence of HIV, hepatitis B virus, and hepatitis $C$ virus infections among males in Rhode Island prisons. Am J Public Health. 2004; 94(7):1218-23.

72 Strang J, Babor T, Caulkins J, Fischer B, Foxcroft D, Humphreys K. Drug policy and the public good: evidence for effective interventions. Lancet. 2012;379(9810):71-83.

73 Rhodes T. Risk environments and drug harms: a social science for harm reduction approach. Elsevier; 2009.

74 McNeil R, Shannon K, Shaver L, Kerr T, Small W. Negotiating place and gendered violence in Canada's largest open drug scene. Int J Drug Policy. 2014;25(3):608-15.

75 Olsen $\mathrm{H}$. Open drug scenes and police strategies in Oslo, Norway. J Scand Stud Criminol Crime Prev. 2017;18(2):141-56. 